\title{
Cardiac Output in the Neonatal Period Using Impedance Cardiography
}

\author{
KATE COSTELOLE.'2T JANET STOCKS, ANI) S. (IODFREY \\ Department of Paediatrics and Neonatal Medicine, Hammersmith Hospital, London, England \\ S. N. M()HAPATRA AND D. W. HII.I. \\ Research Departme'nt of Anaesthetics. The Royal college of Surgeons of Lingland, Lincoln's Inn Fields, London. \\ Eingland
}

\begin{abstract}
Summary
This paper describes a study comparing the impedance cardiac output (ICO) with effective pulmonary capillary blood flow (Qpc eff), measured by rebreathing $N_{2} O$, in a group of healthy babies during the neonatal period. The calculation of ICO requires a value for the electrical resistivity of blood, $\rho$. The resistivity of blood was measured on 40 samples of neonatal blood with hematocrit range of $18-70 \%$ and a new relationship was defined between haematocrit and resistivity, whereby $\rho=$ 67.919 exp (0.02433 Hct) (Fig. 2). A total of 109 simultaneous measurements of $\dot{Q p c}$ eff and ICO, made from 32 different babies studied upon 41 occasions, was considered for correlafion purposes (Table 2). The different methods are plotted against each other in the graphs (Fig. 3). It is seen that using any one of the available data for human blood resistivity alone, a good correlation between ICO and $\dot{Q p c}$ eff is only achieved over a part of the haematocrit range. A hematocrit-related correction factor, $S$, has been derived to be applied to the stroke volume equation. The corrected ICO compared with $\dot{Q p c}$ eff results is shown in Figure 5 and the correlation coefficients and percentage differences between the two methods for the different hematocrit groups are shown in Table 2. The mean ICO is 205 ml kg ' min ', SEM 3.5 (range 124-289).

Impedance cardiography is a safe and easy technique to apply to the newborn human infant but even if accurate values for resistivity are used, a further hematocrit-related factor should be applied for optimal results.
\end{abstract}

\section{Speculation}

A technique having been established by which impedance cardiography can be used to make accurate measurements of cardiac output in the healthy newborn infant, it is now possible to use this method to provide noninvasive observations on the normal cardiovascular physiology of the newborn and to assess its potential for making clinically useful measurements on sick infants.

The method which has been most widely used for the moninvasive quantification of cardiac output in the newborn human infant is the measurement of the effective pulmonary capillary blood flow (Ope eff) by the rebreathing of a soluble incrt gas $(3,4,6,10,23,24)$. This technique is valid if there is normal cardiovascular and respiratory function, but in a baby with respiratory discase. when there is likely to be an uneven distribution of ventilation and perfusion or shunting of blood, it cannot yicld reliable information.

lmpedance cardiography, which is alleged to measure cardiac output by detecting the transthoracic impedance changes associated with the cardiac cycle, has been assessed in adults and children by comparison with invasive methods with encouraging results (1,9,12,14-16,18,19).

To our knowledge, this method has not previously been used in infants. This paper describes a study comparing impedance cardiac output (ICO) with Ope eff. measured by rebreathing nitrous oxide $\left(\mathrm{N}_{2} \mathrm{O}\right)$ ) in a group of healthy babies during the neonatal period.

\section{MATERIALS ANI METHOISS}

IMPEIDANCE: (ARDIOGRAPHY

The instrument used to measure the cardiac output in this study was a Minnesota impedance cardiograph. mode! 304A. This utilizes four disposable aluminized Mylar strip electrodes. In the adult two of these are placed around the neck. with the third just below the xiphisternum and the fourth at least $3 \mathrm{~cm}$ distal to the third. A constant sinusoidal alternating current of 4 ma rms at $100 \mathrm{kHz}$ is passed longitudinally between the outer two electrodes. The product of this current and the transthoracic impedance. $Z_{1}$ ohms. obeying Ohms law, generates a voltage which varies with the cardiac cycle and which is recorded between the two inner electrodes by a high input impedance lincar amplifier. In this study, the outputs taken from the machine were: the mean transthoracic impedance, $Z_{4}$ ohms. given in digital display by the machine; the first derivative of the impedance cardiogram. dZ/dt ohm sec 1 ; an ECG recorded between the outer two electrodes and a phonocardiogram, the latter two signals being used as timing devices.

It was impossible to put two electrodes around the short neck of a young baby. The first electrode was therefore placed on the brow. It was found that the mean transthoracic impedance value. $Z_{10}$ ohms. was more stable, and that a better quality of recording was ohtained if electrode jelly was applied to the brow electrode. The apparatus was always switched on and the electrodes applied for at least 10 min before a recording was taticin.

lmpedance cardiograms were obtained while the child lay quictly. any muscular activity causing gross distortion of the trace. A typical satisfactory trace obtained is shown in Figure 1. As the baby breathed. there was an inevitable swing of the bascline around the zero line and in this study care was taken only to analyze beats which were not distorted by the respiratory swing. If this criterion was fulfilled, the beat was analyzed, the height of $\mathrm{dZ} / \mathrm{dt}$ min being measured from the commencement of the steep upstroke, identified with the help of the FCG and phonocardiogram, irrespective of the position of this point with respect to the baseline. This is in contrast to the usual method of analyzing adult impedance cardiograms which are less atfected by respiratory swings and where the height. $\mathrm{dZ} / \mathrm{dt}$ min, is measured from the bascline. Care was taken to analyze the 


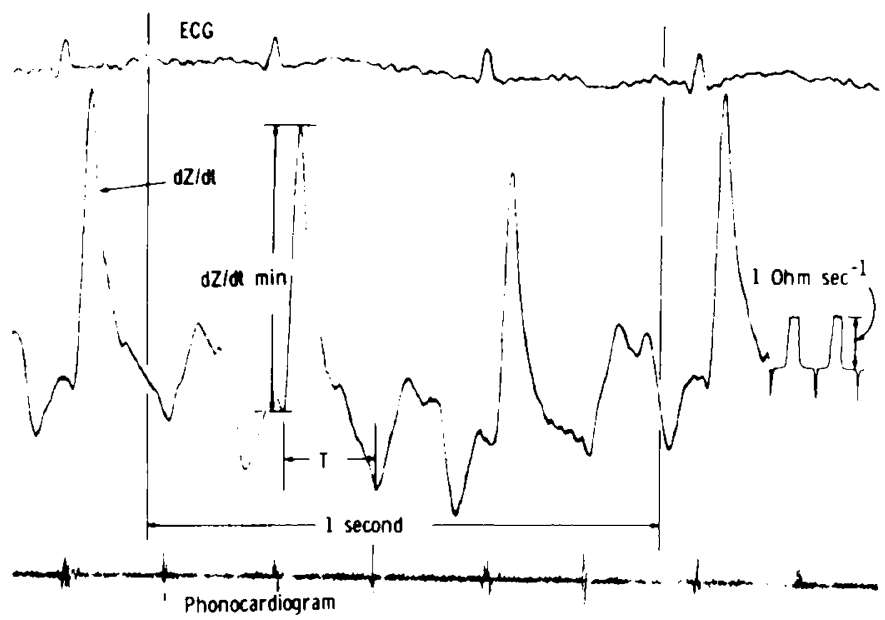

Fig. 1. Typical impedance cardiogram from a quietly breathing baby. showing measurement of the values $\mathrm{d} z / \mathrm{dt}$ min and $\mathrm{T}$.

same number of beats above and below the baseline so that variation of stroke volume during the respiratory evcle was allowed for. It was very unusual for a trace to be so distorted by respiration that it could not be analyzed and usually $8-12$ beats were analyzed.

For each beat analyzed the stroke volume, $\triangle \mathrm{V}$. was calculated from the equation

$$
\mathrm{JV}=\left|\rho\left(\mathrm{L} / \mathrm{Z}_{\mathrm{t} 1}\right)^{2} \cdot \mathrm{dZ} / \mathrm{dt} \min \cdot \mathrm{T}\right| \mathrm{m} \mid
$$

where $\rho$ is the resistivity of human blood at $37^{\circ}$ in ohm $\mathrm{cm} .1$. is the mean distance between the two inner recording electrodes in centimeters. $Z_{0}$ is the mean transthoracic impedance in ohms. $\mathrm{dZ} / \mathrm{dt} \min$ is the maximum negative value of $\mathrm{dZ} / \mathrm{dt}$ occurring during the cardiac cycle in ohms see 1 , and $T$ is the ventricular ejection time in seconds. The values of $\mathrm{dZ} / \mathrm{dt} \mathrm{min}$ and $T$ were obtained from the tracing as shown in Figure 1 and the IC() was calculated from the formula

$$
\mathrm{ICO}=(\text { mean } \Delta \mathrm{V} \times \mathrm{HR}) \mathrm{ml} \min { }^{\prime}
$$

where $H R$ is the heart rate in heats min '.

\section{RESISIIVITY OF BLOOD}

The resistivity of blood is related to the hematocrit. which was determined for each baby from a heelprick specimen of blood spun for 5 min on a Hawksley microhematocrit centrifuge. When this study was undertaken. four relationships between resistivity and the hematocrit of blood had heen published. Those of Kubicek (17) and of Geddes and Sadler (11) are exponential and were derived from work with reconstituted time-expired bank blood. The more recent relationships derived by Hill and Thompson (1.3) and Mohapatra and Hill (21) are linear and are based on measurements made on fresh samples of blood drawn from adult patients from a renal dialysis unit with hematocrits ranging from 16-52?\%

The electrical resistivity of fresh samples of blood from fit human subjects has not previously been measured and this was performed as a part of the current investigation. During the neonatal period a wide hematocrit range is encountered. In order to obtain blood samples covering this range. samples were collected from fresh placentas and from anemic infants immediately before transfusion. The resistivity was measured br a modification of the technique used by Hill and Thompson (13) which could measure the resistivity of samples of blood as small as $11.3 \mathrm{ml}$ (22). Forty blood samples of hematocrit range $18-711$ ", were measured and a new relationship was defined between hematocrit and resistivity. $\rho=67.919$ exp (0.024.3.3 (Hct $\%)(r=0.941)$. This relationship is compared with those previously described in Figure 2 and it can be seen that these data give a higher value for the resistivity than any of the previous datit.

The ICOS reported in this study atre denoted in four different ways, using four different resistivity values abbreviated thus: $\mathrm{ICO}(\mathrm{K})=\mathrm{ICO}$ calculated using resistivity data of Kubicek (17); $\mathrm{ICO}(\mathrm{G \& S})=\mathrm{ICO}$ calculated using resistivity data of Geddes and Sadler $(11) ; I C O(M \& H)=I C O$ calculated using resistivity data of Mohapatra and Hill (21) from work with blood of anemic dialysis patients; ICO $(\mathrm{M} . \mathrm{C} \& \mathrm{H})=\mathrm{ICO}$ calculated using resistivity data of Mohapatra. Costeloe, and Hill (22) from work with placental and neonatal blood samples.

\section{MEASUREMENT OF Qpe eff}

The estimation of the effective pulmonary capillary blood flow. $\dot{Q p e}$ eff. by the rebreathing of nitrous oxide, $\mathrm{N}_{2} \dot{\mathrm{O}}$, relies upon the principle that the gas is absorbed into the bloodstream in proportion to the pulmonary blood flow and the concentration

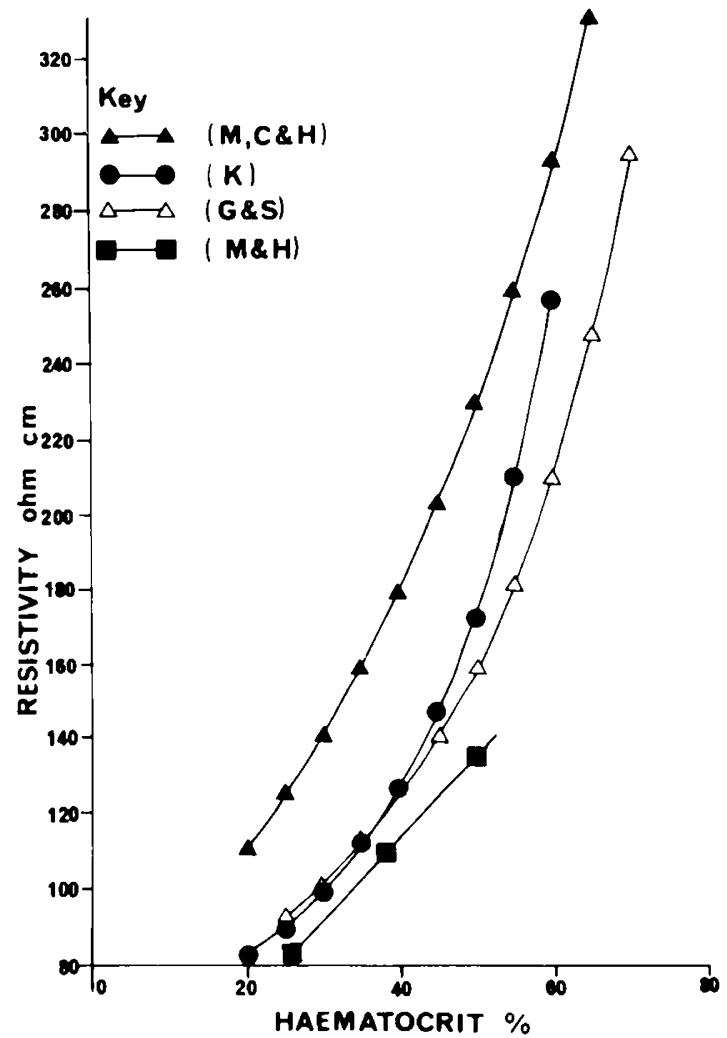

Fig. 2. Ciraphs showing different relationships hetween blood resistivity and hematocrit. (M.C\&H): neonatal blood resistivity. Mohapatra, Costeloc, and Hill (22); (K): Kubicek resistivity data (18); (G\&S): (jeddes and Sadler resisitivity data $(11)$ : $(\mathrm{M \& H})$ : Mohapatra and Hill resistivity data (21).

Table 1 . Reproducibility of effective pulmonary capillary blood flow $\left(\dot{Q} p e^{\prime}\right.$ eff) and impedance cardiac output $(I C O)(M, C \& H)$

\begin{tabular}{|c|c|c|c|c|}
\hline & \multicolumn{2}{|c|}{ Òpe eff, $\mathrm{ml} \mathrm{kg}^{1}(n=4())$} & \multicolumn{2}{|c|}{$\begin{array}{c}\mathrm{ICO}(\mathrm{M}, \mathrm{C} \& \mathrm{H}), \mathrm{ml} \mathrm{kg}^{\prime} \min 1 \\
(n=4(0)\end{array}$} \\
\hline & Obs 1 & Obs 2 & Obs 1 & Obs 3 \\
\hline Mean & 203.5 & 208.5 & 258.4 & 259.6 \\
\hline ¡EM & 4.2 & 4.9 & 9.1 & 9.6 \\
\hline 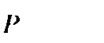 & \multicolumn{2}{|c|}{0.25} & \multicolumn{2}{|c|}{0.82} \\
\hline 'VPE: & \multicolumn{2}{|c|}{5.68} & \multicolumn{2}{|c|}{3.01} \\
\hline
\end{tabular}
measurements 
of $\mathrm{N}_{2} \mathrm{O}$ in the alveoli. The blood flow is then calculated from the equation

$$
\text { Opc cff }=\begin{aligned}
& \mathrm{VN}_{2} \mathrm{O} \times 60 \\
& \mathrm{FAN}_{2} \mathrm{O} \times \alpha
\end{aligned} \mathrm{ml} \mathrm{min} \quad
$$

where $\mathrm{VN}_{2} \mathrm{O}$ is the rate of volume uptake of $\mathrm{N}_{2} \mathrm{O}$ in $\mathrm{ml} \mathrm{sec} 1$ BTPS. FAN.O is the mean fractional alveolar concentration of $\mathrm{N}_{2}(\mathrm{O})$ during the period of analysis. $\alpha$ is the solubility of $\mathrm{N}_{2}(\mathrm{O})$ in blood at $37^{\circ}(=0.47 \mathrm{ml}$ BTPS $\mathrm{ml}$ ' atmosphere ' B'TPS $)$.

The procedure was carried out within an infant whole body plethy'smograph. This was a modified 31.5-liter (ross box (7) with an amplitude freguency response which was flat to within $\pm 5 \%$ from $0-10 \mathrm{cpm}$. The rebreathing apparatus comprised a facemask (Rendell Baker size ()) leading to two taps which were operated pneumatically from outside the box so that the bahy could breathe air from the box or gats from the 500()$-\mathrm{ml}$ bag (Air Med Ltd.). During rebreathing, gas was circulated from a sampling port drilled in the face mask at a rate of $60-90) \mathrm{ml}$ min' through a nitrous oxide meter (Grubb Parsons Med. 1) and returned to the rebreathing bag, via a three-way tap, using a pump situated outside the plethysmograph. The bag could be emptied and filled through this same three-way tap so that, once in place, the lid of the plethysmograph did not have to be disturbed. The box could be vented through a large stopeock situated in its side. Box pressure was measured by a manometer (Mercury Fiectronics micromanometer) and was calibrated in terms of volume by slowly withdrawing gas from the box at a known constant flow rate. All recordings were made using a multichannel amplifier. S.F. Labs. S.E. 4910, and tracings
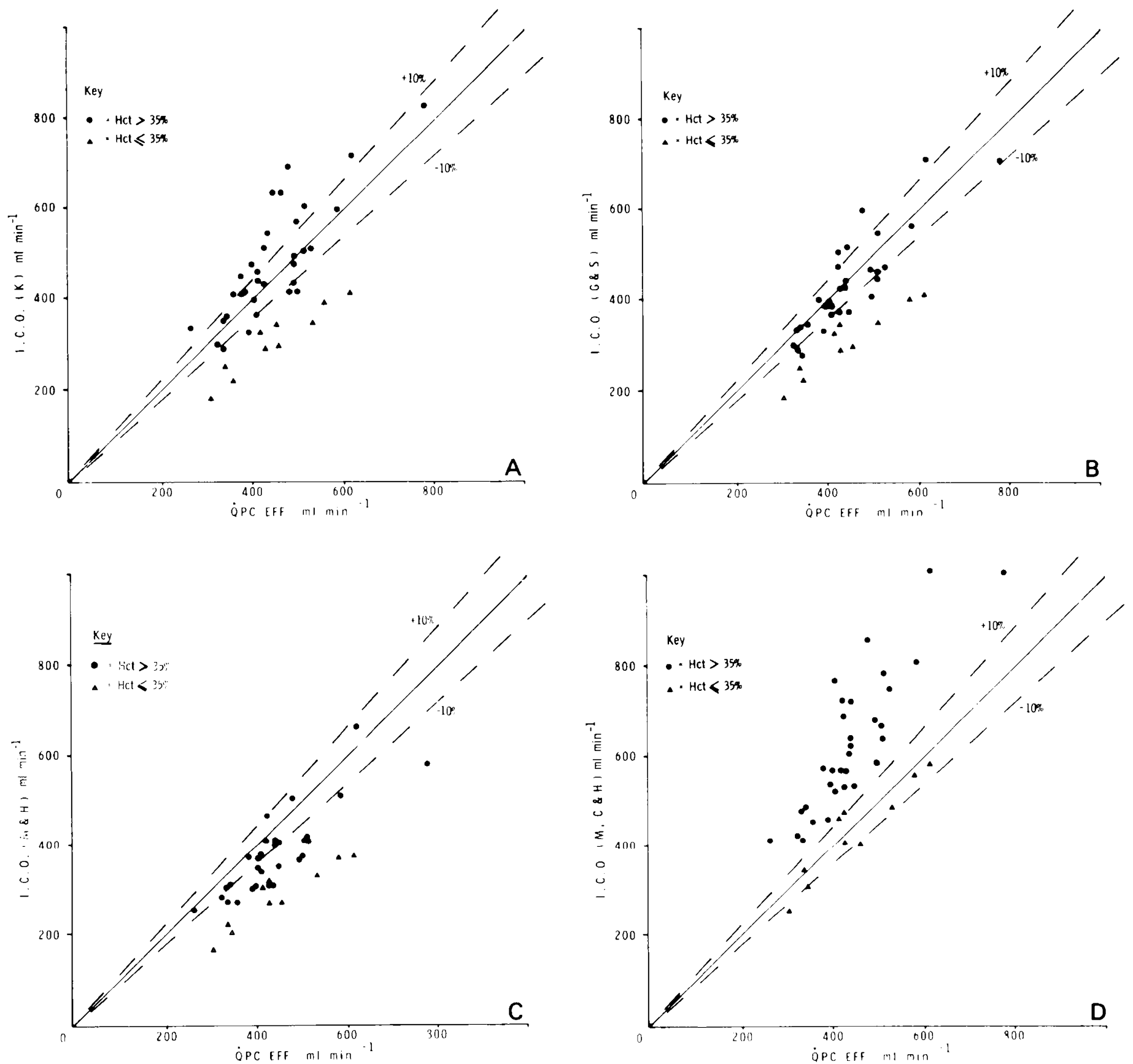

Fig. 3. (iraphs showing relationship between effective pulmonary capillary blood flow ( $(p)$ e ff) and impedance cardiac output ( $I$.C $(O)$.) results with $\pm 10 \%$ deviation. The four different graphs represent four different calculations of $I(O)$ using the different data for blood resisitivity shown in Figure 2. 
were made on Kodak Linagraph direct print photographic paper using an ultraviolet light recorder, S.E. Labs. S.E. 3006.

The baby, swaddled in blankets, with the impedance tape electrodes already in place, was lain within the plethysmograph and the facemask was gently lowered into position, a seal being achieved by means of silicone putty (J. A. Carter L.td., Wiltshire). The lid of the plethysmograph was secured and a volume, equivalent to the estimated functional residual capacity of the infant, of a mixture of $30 \%$ oxygen and $70 \%$ nitrogen, was injected into the bag.

The baby breathed air from the plethysmograph until the box pressure was stable, indicating that equilibrium had been achieved with room conditions. With the box closed, the taps were then switched so that he breathed the oxygen/nitrogen mixture from the bag and the pump was started so that the gases circulated. Rebreathing was continued for $30 \mathrm{sec}$. the box pressure being recorded. The fall in box pressure while rebreathing $\mathrm{O}_{2} / \mathrm{N}_{2}$ was caused by the falling respiratory exchange ratio, ( = CO.2 production/O.2 consumption) and was used in the subsequent calculation as the control slope.

The $\mathrm{O}_{2} / \mathrm{N}_{2}$ mixture was then replaced with a mixture containing $30 \% \mathrm{O}_{2}$ and $70 \% \mathrm{~N}_{2} \mathrm{O}$. and the rebreathing procedure was repeated. The change in box pressure, the concentration of $\mathrm{N}_{2} \mathrm{O}$ sampled from within the face mask, and the impedance cardiogram were recorded simultaneously. Upon this occasion the change in box pressure related to both the $\mathrm{N}_{2} \mathrm{O}$ uptake and the falling respiratory exchange ratio.

It was found that equilibrium between the bag and the alveoli in terms of nitrous oxide concentration was usually achieved within $8 \mathrm{sec}$ of commencing rebreathing, and the period between 10 and $20 \mathrm{sec}$ was analyzed for Qpe eff unless there was evidence of recirculation of $\mathrm{N}_{2} \mathrm{O}$-containing blood before this time, as indicated by a sudden reduction in $\mathrm{N}_{2} \mathrm{O}$ uptake, in which case the period of analysis was adjusted accordingly.

A factor to correct for the small leak in the plethysmograph was applied to both the control and test slopes, and the fall in box pressure attributable to $\mathrm{N}_{2} \mathrm{O}$ uptake alone was obtained from the difference between the corrected slopes. This value was converted to volume by application of the calibration factor. Substituting the calculated rate of $\mathrm{N}_{2} \mathrm{O}$ uptake for $\mathrm{VN}_{2} \mathrm{O}$ in Fquation 3, together with the value for FAN $N_{2}($ ) obtatined from the tracing. Opc eff was estimated. A more detailed account of the physical properties of the plethysmograph together with the derivation of the equation to correct for pressure leakages is presented elsewhere (24).

As the infant rebreathed the $\mathrm{N}_{2} \mathrm{O}$ mixture. a simultaneous impedance cardiogram was performed and the ICO and $\dot{Q p e}$ eff were calculated over precisely the same time period. Whenever possible. three sets of simultaneous data were recorded from each bahy each time he was studied.

In this paper the results of both ICO and Qpe eff measurements are expressed in milliliters per min for the purposes of correlation and in milliliters per kg per min for comparison with the results of other workers.

\section{REPRODUCIBII.ITY}

The reproducibility of both Qpe eff and IC O was investigated by performing a paired $t$-test on the first two of each set of observations for each method and by calculating the coefficient of variation of paired estimates $(8)$ (CVPE) on the same data by the formula, CVPE $=(S D d / \bar{\chi}) \times 1() 0 \%$, where SDd is the standard deviation of the difference hetween the pairs of observations and $\bar{\chi}$ is the mean of all the observations. The results of this analysis are given in Table 1 which shows good reproducibility for both methods of measuring cardiac output.

\section{SUBJEC "TS}

The infants included in this study were all patients on the Premature Baby Unit at the Hammersmith Hospital. There was no selection in respect of gestational age, hirth weight, or weight and age at the time of testing. and none had clinical evidence of cardiovatscular or respiratory abnormality. Any baby in whom left to right shunting was indicated by the recirculation of $\mathrm{N}_{2} \mathrm{O}$ carrying blood before equilibration had been achieved was excluded from the study. The technique of estimation of Qpe eff by rebreathing $\mathrm{N}_{2} \mathrm{O}$ has been used with healthy babies by other workers. The use of the impedance method caused no additional risk or discomfort and both methods have been approved by the Ethics Committee of this hospital.

\section{RESULTS}

A total of 109 simultaneous measurements of $\dot{Q p c}$ eff and ICO from 32 different infants studied upon 41 occasions were considered for correlation purposes. The data for these infants and Qpe eff and ICO determinations using the different resistivity values are given in Table 2 and the different methods are plotted against each other in the graphs (Figure 3) showing the line of identity with $\pm 10 \%$ deviation. It is seen that, using the Kubicek (17) and the Geddes and Sadler (11) resistivity data, the impedance technique underestimates values in those infants whose hematocrit was below $35 \%$.

The Mohapatra and Hill (21) data produces a greater tendency to underestimation. In contrast, using the Mohapatra, Costeloe, and Hill (22) data from work with neonatal blood samples, the correlation is acceptable in the anemic group but the ICO is overestimated in the $\mathrm{Het}>35 \%$ group.

Using the mean value for Qpe eff each time an infant was studied as the standard. a correction factor. $S$, to be applied to the ICO calculated using the accurate resistivity data, $\rho$ [ICO $(\mathrm{M}, \mathrm{C} \& \mathrm{H})]$ (Fig. 2), was derived, so that for each set of values, $S=[$ Qpe eff $) /(I C O(M . C \& H)]$. The values obtained for $S$ for each occasion an infant studied were then related to the relevant hematocrit value and nonlinear regression analysis to find the line of best fit was performed (Fig. 4).

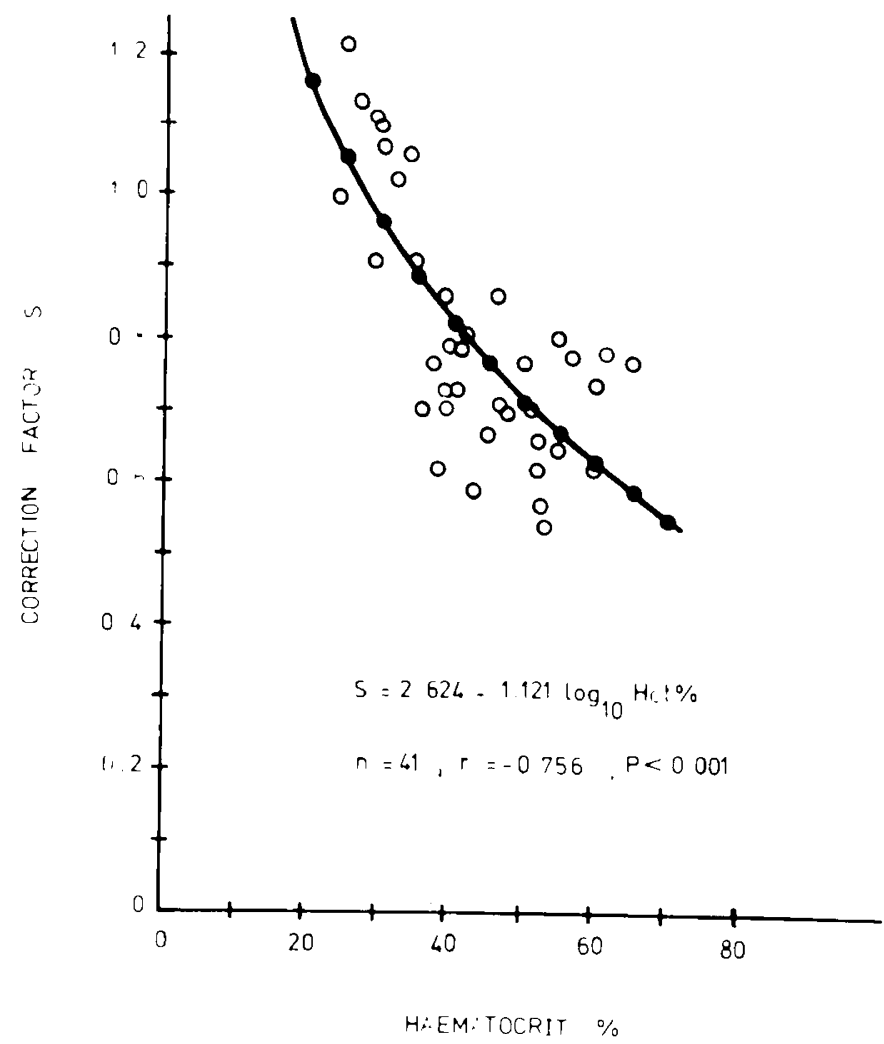

Fig. 4. Craph showing the relationshp between the correction constant $S . S=$ Qpe eff/ICO $(M . C \& H)$ ( the regression line, $S=2.624-1.121 \log _{10} \mathrm{Hct}$. 
Table 2. Data for infants and results of effective' pulmonary capillary blood flow (Qpe effland impedance cardiac outpat (IC (O) e'stimation'

\begin{tabular}{|c|c|c|c|c|c|c|c|c|c|c|c|c|c|}
\hline & Subject & (jA & $B W$ & Age & $W t$ & L. & $\mathrm{HCt}$ & Opceff & $\mathrm{ICO}(\mathrm{K})$ & $\begin{array}{c}\text { ICO } \\
\text { (Ci\&S) }\end{array}$ & $\begin{array}{c}\mathrm{ICO} \\
(\mathrm{M} \& \mathrm{H})\end{array}$ & $\begin{array}{c}\mathrm{ICO} \\
(\mathrm{M}, \mathrm{C} \& \mathrm{H})\end{array}$ & $\begin{array}{c}\text { ICO } \\
(\mathrm{M}, \mathrm{C} \& \mathrm{H}) \\
\text { (S) }\end{array}$ \\
\hline \multirow{9}{*}{$\mathrm{Hct} \leqslant 3.5 \%$} & la & 30 & 1140 & 58 & 2160 & 45.5 & 29 & 46.3 & 295 & 298 & 272 & +12 & 406 \\
\hline & $\mathrm{lb}$ & 30) & 1140 & 81 & 2220 & 46.0 & 30) & 5.39 & 349 & 352 & 328 & +92 & 476 \\
\hline & 2 & 30) & 1500 & 26 & 1720 & 44.0 & 27 & 352 & 223 & 226 & 203 & 308 & 314 \\
\hline & 3 & 33 & 2340 & 14 & $22(100$ & 47.4 & 34 & 4.35 & 292 & 290 & 271 & 410 & 372 \\
\hline & th & 34 & 1530 & 37 & 23.30 & 4.3 .5 & 35 & 421 & 326 & 326 & 306 & 46.3 & 414 \\
\hline & $5 a$ & 30) & 1340 & 36 & 1660 & 42.0 & 25 & 312 & 184 & 187 & 166 & 344 & 270 \\
\hline & $5 b$ & 30 & 1.340 & 49 & 2050 & 43.5 & 24 & 345 & 251 & 253 & 222 & 560 & 370 \\
\hline & 6 & 30 & 1320 & 52 & 2640 & 48.0 & 31 & 589 & 391 & 403 & 372 & 478 & 533 \\
\hline & 7 & 28 & 10.30 & 56 & 2050 & 43.0 & 29 & 434 & 344 & 346 & 316 & 583 & 471 \\
\hline Mean & 8 & & & & $2+20$ & 45.5 & 30 & 621 & +13 & +11 & 376 & 256 & 565 \\
\hline $\begin{array}{l}\text { Mean } \\
\text { SEM }\end{array}$ & & $\begin{array}{r}30.6 \\
0.6\end{array}$ & $\begin{array}{r}14(1) 9 \\
129\end{array}$ & 6.6 & $\begin{array}{r}2012 \\
185\end{array}$ & $\begin{array}{l}+5.8 \\
0.62\end{array}$ & $\begin{array}{r}\% \text { difference } \\
\text { Ope eff }\end{array}$ & from ${ }^{r}$ & $\begin{array}{c}0.93 \\
-32\end{array}$ & $\begin{array}{l}0.94 \\
-31\end{array}$ & $\begin{array}{l}0.94 \\
-37\end{array}$ & $\begin{array}{l}0.94 \\
-5\end{array}$ & $\begin{aligned} & 0.93 \\
- & 7\end{aligned}$ \\
\hline \multirow[t]{31}{*}{$\mathrm{Hct}>3.5 \%$} & $4 a$ & 34 & 1530 & 26 & 1960 & +2.5 & 47 & $3+1$ & 355 & 335 & 306 & 482 & 362 \\
\hline & 9 & 34 & 20000 & 32 & 2220 & 46.0 & 55 & +3.3 & 343 & 376 & 309 & 535 & 360 \\
\hline & $10 a$ & 31 & 1.320 & 23 & 1500 & +1.0 & 47 & 347 & 361 & 340 & 308 & 484 & 366 \\
\hline & $I 0 b$ & 31 & 1.320 & 37 & 1800 & +2.5 & 37 & 3.30 & 302 & 301 & 282 & 426 & 369 \\
\hline & $11 a$ & 29 & 1200 & 36 & 1900 & 44.0 & 39 & 446 & 4.36 & +29 & 400 & 611 & 514 \\
\hline & $11 \mathrm{~b}$ & 29 & 1200 & 48 & 2340 & 46.5 & 41 & 414 & 369 & 367 & 342 & 526 & 429 \\
\hline & 12 & 34 & 2200 & 17 & 2320 & +9.0 & 39 & 449 & 447 & 440 & 411 & 628 & 527 \\
\hline & 1.3 & 36 & 2120 & 1.3 & 2240 & 45.0 & 39 & 397 & 329 & 325 & 304 & 464 & 389 \\
\hline & 14 & 35 & 2050 & 55 & 3330 & 52.0 & 38 & 626 & 716 & 710 & 667 & 1012 & 862 \\
\hline & 1.5 & 38 & 2740 & 16 & 2580 & 49.5 & 46 & 505 & 419 & 409 & 374 & 590 & 448 \\
\hline & 16 & 32 & 1800 & 22 & 2130 & 46.0 & 45 & 388 & 418 & 402 & 371 & 578 & 445 \\
\hline & 17 & 40 & 2940 & 5 & 2920 & 51.0 & 41 & 594 & $6(0)$ & 56.5 & 515 & 810 & 661 \\
\hline & 18 & 35 & 1500 & 2.3 & 2090 & 46.5 & 48 & 449 & 477 & $4+5$ & 403 & 644 & 476 \\
\hline & 19 & 34 & 2440 & 17 & 26000 & 50.5 & +2 & 518 & 461 & $4+9$ & +19 & 643 & 517 \\
\hline & $20 a$ & 33 & 1860 & 14 & 1920 & 4.3 .0 & 61 & 36.3 & +14 & 346 & 270 & 4.57 & 28.5 \\
\hline & $20 b$ & 3.3 & 1860 & 25 & 2270 & 46.5 & 55 & 485 & 694 & 6012 & 509 & 857 & 577 \\
\hline & $20 c$ & 33 & 1860 & 28 & 2380 & 46.5 & 51 & 535 & 514 & 475 & 413 & 751 & 533 \\
\hline & 21 & 40 & 3540 & 2 & 3500 & 52.5 & 52 & 521 & 609 & 549 & 465 & 786 & 550 \\
\hline & 22 & 37 & $2+80$ & 7 & 2400 & 45.5 & 53 & +15 & 4.38 & 388 & 378 & 769 & 384 \\
\hline & 23 & 32 & 1500 & 10) & 1400 & +2.0 & 55 & 268 & 3.35 & 290 & 255 & 413 & 278 \\
\hline & 24 & 38 & 2780 & 8 & 2980 & +9.0 & 50 & 517 & 507 & 464 & 415 & 668 & 480 \\
\hline & 2.5 & 32 & 2120 & 21 & 2160 & & 36 & $4(18$ & 401 & 396 & 371 & 573 & 503 \\
\hline & 26 & 32 & 1500 & 41 & 2500 & 47.5 & 40 & 455 & $3 \times 0$ & 375 & 353 & 537 & 445 \\
\hline & $27 a$ & & 2180 & 5 & 2080 & & 52 & 4.31 & 538 & 484 & +12 & 692 & 485 \\
\hline & $27 b$ & & 2180 & 11 & 2170 & & +3 & +30 & 518 & 505 & 469 & 726 & 576 \\
\hline & 28 & 31 & 1080 & 35 & 1550 & +1.0 & 40 & 342 & 294 & 291 & 273 & 416 & 344 \\
\hline & 29 & 40 & 3200 & 7 & 30000 & 51.5 & 57 & 786 & 825 & 708 & 587 & 1003 & 6.58 \\
\hline & $30 a$ & 38 & 1960 & 7 & 2080 & 46.5 & 60 & 450 & 6.36 & 519 & +10 & 721 & 455 \\
\hline & $30 h$ & 38 & 1960 & 15 & 2340 & 47.5 & 60 & 503 & 574 & 468 & 371 & 681 & 430 \\
\hline & 31 & 38 & 1700 & 9 & 1850 & 45.0 & 65 & 4.38 & 547 & 426 & 304 & 569 & 337 \\
\hline & 32 & 38 & 2680 & 2 & 2600 & 38.5 & 60 & 402 & 477 & 389 & 306 & 540 & 341 \\
\hline Mean & & 34.7 & 2028 & 20 & 2286 & 46.2 & & $r$ & 0.83 & 0.88 & 0.85 & 0.86 & \\
\hline SEM & & 0.6 & 113 & 2.5 & 87 & 00.68 & $\%$ difference & from & +6 & -3 & -14 & +40 & +3 \\
\hline
\end{tabular}

$$
\text { Qpe eff }
$$

1 Hot : Hematocrit \%: BW: hirth weight at time of testing in grams; (BA: gestational age in weeks: age: age at time of testing in days: L: crown-hed length in centimeters; ICO: impedance cardiac output. expressed in milliliters per min; ICO) (S): ICO calculated using the correction factor "S" (see text); $r$ : correlation coefficient between Ope eff and ICO.

The equation of the regression line is: $S=2.624-1.121$ $\log _{111} \mathrm{Het} ; r=-0.756 ; p<0.001$. The results for $1 \mathrm{CO}$ were then recalculated using this hematocrit-related correction factor in association with the true neonatal hlood resistivity, $\rho$ [ICO $(\mathrm{M}, \mathrm{C} \& \mathrm{H})]$, so that the impedance equation for calculation of stroke volume becomes

$$
\Delta V=S\left(\rho\left(L / Z_{0}\right)^{2} \cdot \mathrm{dZ} / \mathrm{dt} \min \cdot \mathrm{T} \mid \mathrm{ml}\right.
$$

These data are shown in the last column in Table 2, and are related to the Ope eff data in Figure 5. The mean ICO is 205 $\mathrm{ml} \mathrm{kg}^{1} \mathrm{~min}{ }^{\prime}$. SEM \pm 3.5 , range $124-289 \mathrm{ml} \mathrm{Kg}^{\prime} \mathrm{min}{ }^{\prime}$, which compares favorably with values for measurements of Opc eff made by other workers in babies over $48 \mathrm{hr}$ old (Table 3 ).

\section{DISCUSSION}

This study has shown that impedance cardiography is a safe and easy technique to apply to the newhorn human infant but that using any one of the available data for human blood resistivity alone, a good correlation between ICO and Ope eff is achieved only over a part of the encountered hematocrit range. It is ethically unaceptable to make invasive measurements of 


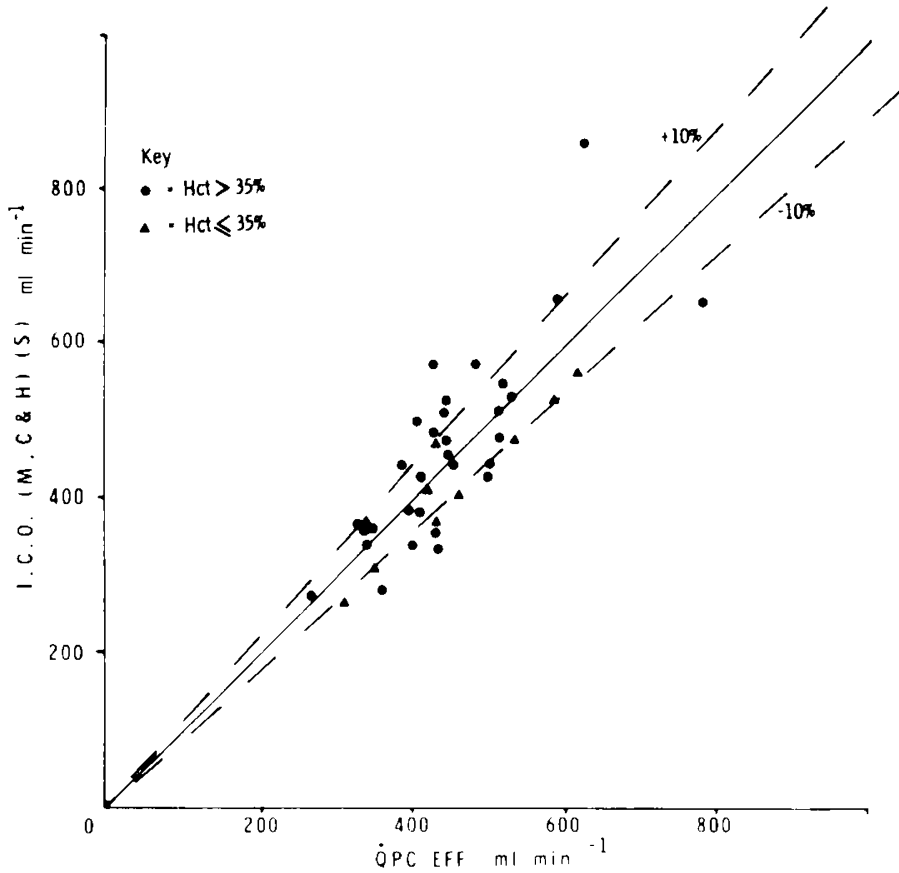

Fig. 5. Graph showing the corrected impedance cardiac output (22), $I C O(M C \& H)(S)$, against effective pulmonary capillary blood tlow $(\dot{Q P C E F F})$, with $\pm 10 \%$ deviation

Table 3. Previous mesurements of effective pulmonary capillary blood flow (Qpe eff) in infants over $48 \mathrm{hr}$ old

Author Ope eff \pm SEM. $\mathrm{ml} \mathrm{kg}{ }^{\prime} \min { }^{1}$

Chu et al. $1967(4)$

Cotton et al. 1971(6)

Brady and Rigatto, 1971 (3)

Orme et al.. $1973(23)$

$$
\begin{aligned}
& 229 \pm 15.6 \\
& 16.5 \pm 25.6 \\
& 200 \pm 6.6 \\
& 184 \pm 0.5
\end{aligned}
$$

cardiac output on normal infants because of the risks of anesthesia and catheterization; thus the noninvasive technique of estimation of Qpe eff was used as a standard in this study. It is generally acknowledged that this method does not give a valid indication of cardiac output when there is respiratory or cardiovascular abnormality, but in normal adults it has been shown to correlate well with invasive measurements of cardiac output both at rest (20) and with exercise (2).

The technique as described in this study was highly sensitive in detecting any persistent left to right fetal shunt, which involved exclusion from the study. This complication was encountered in $20 \%$ of preterm infants, up to 2 weeks of postnatal age but bevond this age it was rare. The ICO in these babies tended to be higher than in those who were not shunting. This phenomenon reduces the potential usefulness of the impedance cardiograph for quantitatively accurate measurement of cardiac output in very young preterm babies. The results of $\dot{\text { Ope eff }}$ estimation were highly reproducible and compare favorably with similar measurements made by other workers $(3,4,6$. 23). The method was therefore regarded as being a satisfactory standard.

The subdivision of the infants into two groups on the basis of hematocrit was done because of the revealed inaccuracies of the impedance method which appeared to be hematocrit related. The two groups were compared in other aspects. There was no significant difference between the weight and length at testing. $P>0.1$. The infants in the low hematocrit group were less mature, lighter at birth, and older at the time of testing, $P<$ 0.01. These observations were felt to reflect characteristics of those babies who later became anemic rather to be a direct cause of correlation failure.
Some of the early evaluations of IC() measurements in the adult assumed a constant value for the resistivity of blood (1. 12, 16, 18). In later studies, values for resistivity related to hematocrit derived from the data of Kubicek or of Geddes and Satder were used $(15.19)$. The hematocrit range encountered in the healthy adults used in these studies was narrow and it was not until Hill and Thompson $(13,14)$ made their study of impedance measurements in anemic patients with renal failure that the importance of obtaining accurate values for blood resistivity was highlighted. Their work with fresh blood samples from their patients revealed lower values for resistivity than had been previously reported and their ICO measurements were $21.5 \%$ lower than simultaneous isotope dilution cardiac output measurements. The closely related data of Mohapatra and Hill (21). used in this study. also produced an underestimation. The values for resistivity obtained from samples of neonatal blood in this study were higher than the previous data and use of this data give a mean ICO result for the group with $\mathrm{Hct}<3.5 \%$ that was $4.6 \%$ lower than the mean Ope eff, whereas for the group with $>3.5 \%$, the $1 \mathrm{CO}$ was $40.1 \%$ higher.

Subsequent work (22) has shown that the low values obtained by Hill and Thompson (1.3) and Mohapatra and Hill (21) are peculiar to patients with renal failure, as normal children and adults have blood resistivity similar to that of newborn infants (22). The values obtained by Kubicek (17) and by Geddes and Sadler (11) are considered unreliable since they were obtained from work with reconstituted, time-expired bank blood.

Why, having accurate values for resistivity, the impedance technique should fail in the group of infants with $\mathrm{Hct}>3.5 \%$ is not clear. It has been suggested previously $(5,18)$ that application of a constant to the standard equation for calculation of stroke volume used in this study may be required to correct for factors such as chest shape. The impedance technique has proved so simple to perform and so reproducible that to attempt quantitative improvement of the results in this manner would seem a justifiable exercise. The large scatter of the points in the data from which the constant. S, was derived (Fig. 4) is thought to reflect the nature and variety of the factors being corrected. We now use this correction factor for all ICO calculations, noting that its use is valid only if the impedance measurements atre made as in this study, $i$.e. by meaturing the mean distance between the recording electrodes, estimating the hematocrit on a specimen of blood obtained by prick using a lancet rather than by venipuncture, and ising the relationship between resistivity of blood and hematocrit. $\rho=67.919 \exp (0.024 .33 \mathrm{Hct})$ derived from work with fresh neonatal blood samples (22).

Impedance cardiography and rebreathing techniques are preferable to other methods of estimating cardiac output in the newborn in that they are noninvasive. Impedance cardiography is easier to perform than a rebreathing procedure and once the clectrodes are applied. repeated measurements can be made without any further handling of the baby. In addition, it has the advantage over all other methods of providing quantitative beat to beat information as opposed to a mean flow. In this age group it is essential to estimate the hematocrit because of the wide range encountered, but even if accurate values for resistivity are used. a further hematecrit-related correction factor should be applied for optimal results.

\section{REFERIN('ES ANI) NOTES}

1. Baker. I. F., Judy, W. V.. (ieddes, L. I.. Langley, F. M., and Hill, D. W Measurement of cardiac output by means of electrical impedance. Cardiovas. Res. Center Bull. 9: 135 (1971)

2. Becklake, M. R., Jarvis, (. I. Pengelly, L.D). Kenning, S., Mc(jregor, M and Bates, D. V.: Measurement of pulmonary blood flow during exercise using nitrous oxide. J. Appl. Physiol., 17: 579 (1962).

3. Brady. J. P., and Rigatto. H.: Pulmonary capillary hlood flow in newborn infants using plethysmography and nitrous oxide. Pediatrics, 48: 207 (1971).

4. Chu, J. Clements, J A Cotton, F K Klaus, M H Suct A Y and Bradley. W. H.: Neonatal pulmonary ischaemia. Part 1. Clinical and physiological studies. Pediatrics, 40: 709 (1967).

5 . Conley, W. L.: The calculation of cardiac stroke volume from variations in 
transthoracic electrical impedance, Biomed. Fng., 7: 316 (1972)

6. Cotton. E. K., Cogswell, J. J., and Cropp, G. J. A.: Measurements of effective pulmonary blood flow in the normal newborn infant. Pediatrics. 47: $520(1971)$

7. Cross, K. W.: The respiratory rate and ventilation in the newborn baby. J. Physiol. 109: 459 (1949)

8. Dahlberg, G.: Staristical Methods for Medical and Biological Students. p. 122 Allen \& Unwin and Interscience Inc., London and New York, (1940)

9. Denniston, J. C.. Maher, J. I., Reeves; J. T., Cruz, J. C., Cymerman. A. and Grover. R. F. Measurement of cardiac output hy electrical impedance at rest and during exercise. J. Appl. Physiol., 40:1 (1976).

10. Dinwiddic, R.. and Russell, G.: The measurement of effective pulmonary apillary blood flow in the newhorn using low concentrations of nitrous oxide. Biol. Neonate, 21:83 (1972).

11. Cieddes, 1. A., and Sadler. C.: The specific resistance of blood at hedy temperature. Med. Biol. Eing., 11:336 (197.3)

12. Harley, A., and Greenfield. J. ( .: Determination of cardiac output in man by means of impedance plethysmography. Acrospace Med...39: 248 (1968).

13. Hill, D. W., and Thompson, F. D.: The effect of hasematecrit on the resistivity of human blood at $37^{\circ} \mathrm{C}$ and $10(0) \mathrm{kHz}$. Med. Biol. Fng.. 1.3: 187 (1975)

14. Hill. D. W. and Thompson, F. D.: The importance of blood resistivity in the measurement of cardiac output by the thoracic impedance method. Med Biol. Eng.. 13: $187(1975)$

15. Judy, W. V., Langley, F. M., Mecowen, K. D., Stinnett, D. M., Baker, 1. $E$... and Johnson, P. C.: Comparative evaluation of the thoracic impedance and isotope dilution methods for measuring cardiac output. Acrospace Med. 40): $532(1969)$.

16. Kinnen. E.: Cardiac output from transthoracic impedance variations. Am
N. Y. Acad. Sci., 170: $747(1970)$.

17. Kubicek, W. (i.: Unpublished data supplied with Minneseta impedance cardiograph.

18. Kubicek, W. G.. Karnegis, J. N., Patterson, R. P., Witsoce. D. A., and Mattson, R. H.: Development and evaluation of an impedance cardiac output system. Aerospace Med., 37: 1208 (1966).

14) Lababidi Z Ehmke D A Durnin, R. E.. Leaverton, P. F... and Lauer R. M.: Evaluation of impedance cardiac output in children. Pediatrics, 47 $870(1971)$.

20. 1.inderholm. M. H.. Kimbel, P., Lewis, D. H., and Dubois, A. B.: Pulmonary capillary blood flow during cardiac catheterisation. J. Appl. Physiol., 17: $1.35(1962)$

21. Mohapatra, S, N., and Hill, D. W.: The changes in blood resistivity with haematocrit and temperature. Eur. J. Intensive (are Med., I: 153 (1976)

22. Mohapatra. S. N. (onsteloe K. I... and Hill, I). W.: Blood resistivity and its implications for the calculation of cardiac output by the thoracic electrical impedance technique. Intensive Care Med., 3: 6.3 (1977)

23. Orme, R. L.. Featherhy. E. A., Rigatto, H. Cervantes, F. J., and Brady. J $P$.: Effective pulmonary blood flow in a preterm infants with and without respiratory distress - A simple hedside method using $\mathrm{N}_{2}$ (). Pediatries, 52: $179(197.3)$

24. Stocks, J.. Consteloc. K.. Winlove, C. P... and Codfrey. S. Measurement of pulmonary capillary blood flow in infants by plethysmography. J. C'lin. Invest. 59: 490 (1977).

25. Requests for reprints should be addressed to: Dr. K. Costeloe. University Department of Paediatrics, John Radeliffe Hospital, Oxford OX2 $6 \mathrm{HF}$ (England).

26. Received for publication ()ctober 29, 1970

27. Accepted for publication April 12,1977.
Acidosis

colostrum

electrolytes human milk hyponatremia $\mathrm{pH}$

\title{
Electrolyte and pH changes in Human Milk
}

\author{
(HRISTINE: ANSELL. ANGHLA MOORE. ANI) H. BARRIE:16,
}

Paediatric Research Laboratory, Charing Cross Hospital, London, England

\section{Summary}

Milk samples from 100 lactating mothers in the 10 days following delivery have been analyzed for $\mathrm{pH}$, sodium, and potassium. The sodium concentration was high in the first 5 days, mean $21 \pm 5 \mathrm{mmol} / \mathrm{liter}$, but fell to a mean $15 \mathrm{mmol} / \mathrm{liter}$ by the end of the first week and $12 \mathrm{mmol} / \mathrm{liter}$ by the 10th day. A similar downward trend was shown for potassium with an initial mean concentration of $18.5 \mathrm{mmol} / \mathrm{liter}$ falling to 15 mmol/liter by the 10th day. The $\mathrm{pH}$ fluctuated widely from day to day through a range of $6.75-7.42$ with a mean $p H 7.09$. Considerable variations were shown in individuals from day to day, and from the beginning to the end of feeds (Table 1).

The relatively high sodium concentration in the firsi few days may be an important defense mechanism against dehydration and hyponatremia during a period of relative thirst and starvation. The variation in the $\mathrm{pH}$ and electrolyte content of human milk may be expected to have some influence on the acid-base and electrolyte status of the infant.

\section{Speculation}

Hyponatremia and acidosis in neonates in the first few weeks may be attributed in part to the inappropriate $\mathrm{pH}$ and electrolyte content of artificial milk formulas based on mature human milk. The addition of sodium and base to formulas may be a desirable modification both for premature infants and for term infants in the first few weeks of life.

Renewed attention has recently been paid to the optimal mineral composition of infant feeding formulas, the assumption being that because human milk is physiologic it is less likely to cause electrolyte or acid-base distrubances. The values usually quoted for sodium and potassium concentrations in breast milk, and to which artificial milk formulas aspire. refer to mature milk. although the different concentrations in colostrum and transitional milk have long been recognized (9). The aim of this investigation was to determine the likely intake of sodium and potassium in the first 10 days of life and to establish the normal range of $\mathrm{pH}$ of colostrum and transitional milk.

\section{MATERIALS AND METHODS}

Milk samples were taken with informed consent from a random series of 100 lactating mothers. Milk was also collected from one patient for the 10 consecutive days after delivery. Specimens were collected during the 9 AM feed by hand expression by the mother assisted by one of us (C. Ansell) using a standard technique (2). The breast was cleaned with water only and 5-ml samples were taken into sterile universal containers approximately $1-2$ min after starting the feed and at 